\title{
Pathogenesis of adult-onset Still's disease: new insights from the juvenile counterpart
}

\author{
Yvan Jamilloux $\cdot$ Mathieu Gerfaud-Valentin • \\ Fabio Martinon · Alexandre Belot • Thomas Henry • \\ Pascal Sève
}

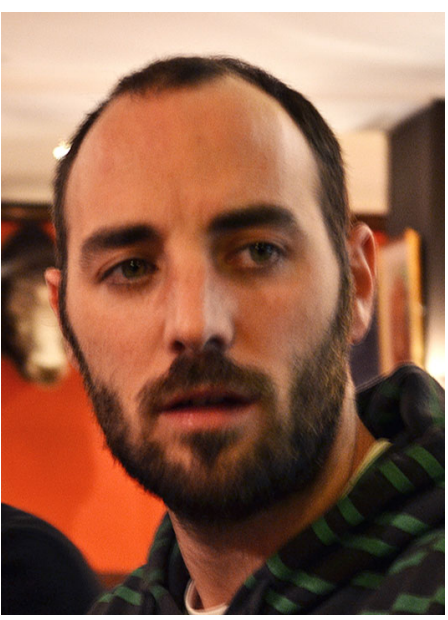

Published online: 12 November 2014

(c) Springer Science+Business Media New York 2014

Yvan Jamilloux

\begin{abstract}
Adult-onset Still's disease (AOSD) is a rare inflammatory disease characterized by the classical triad of daily fever, arthritis, and typical salmon-colored rash. Recent accumulation of knowledge, mostly arising from hereditary autoinflammatory diseases and from the systemic-onset juvenile idiopathic arthritis (sJIA), has given raise to new hypotheses on the pathophysiology of AOSD. In this review, we first discuss on the continuum between AOSD and sJIA. Then, we summarize current hypotheses on the underlying pathogenesis: (1) an infectious hypothesis; (2) an autoinflammatory hypothesis; (3) a lymphohistiocytic hypothesis; and (4) a hyperferritinemic hypothesis. Finally, we present the recent data suggesting that patients with AOSD fall into two distinct subgroups with different courses, one with prominent systemic features and one with chronic arthritis.
\end{abstract}

Keywords Adult-onset Still's disease - Systemic-onset juvenile idiopathic arthritis - Autoinflammatory diseases . Reactive hemophagocytic lymphohistiocytosis $\cdot$ IL-1 $\beta$ IL-18 · Ferritin

Thomas Henry and Pascal Seve have contributed equally to this review.

Y. Jamilloux $(\bowtie) \cdot$ M. Gerfaud-Valentin · P. Sève

Department of Internal Medicine, Hopital de la Croix-Rousse, 103 grande rue de la Croix-Rousse, Lyon 69004, France

e-mail: yvanjamilloux@ @otmail.com

Y. Jamilloux · M. Gerfaud-Valentin · A. Belot - T. Henry ·

P. Sève

University Claude Bernard-Lyon 1, Lyon, France

Y. Jamilloux $\cdot$ F. Martinon

Department of Biochemistry, University of Lausanne, Epalinges, Switzerland

Y. Jamilloux $\cdot$ T. Henry

International Research Center on Infectiology (CIRI), Inserm U1111, CNRS UMR5308-ENS de Lyon, Lyon, France

A. Belot

Department of Paediatric Nephrology, Rheumatology, and Dermatology, Hôpital Femme-Mère-Enfant, Bron 69500, France

\section{Introduction}

Adult-onset Still's disease (AOSD) is a rare inflammatory disorder characterized by the classical triad of daily fever, arthritis, and typical salmon-colored rash. The epidemiology, diagnostic criteria, classification, and treatment of AOSD have been reviewed recently [1]. Yet, the pathophysiology of this disease remains obscure and the identification of an etiologic trigger is still lacking. Over the last decade, the understanding of cellular mechanisms that contribute to mounting effective and balanced immune responses has greatly improved. One striking event was the characterization of autoinflammatory disorders leading to a renewed classification of immune-mediated rheumatic diseases [2]. Data from genetic and immunologic studies, together with clinical trials of biologic treatments, have also contributed to gain a better understanding of AOSD pathophysiology.

The juvenile Still's disease, now preferentially called systemic-onset juvenile idiopathic arthritis (sJIA), is considered as a subtype of juvenile idiopathic arthritis (JIA) [3]. However, evidence suggests that sJIA should be considered 
apart from this spectrum of diseases because of clear differences in epidemiology, clinical manifestations, pathophysiology, and response to treatment [4]. Indeed, sJIA is more likely to belong to the autoinflammatory diseases following the same continuum as AOSD. However, whether sJIA and AOSD are the same disease or not is still a matter of controversy. The higher incidence of sJIA, as compared to AOSD, certainly accounts for the much more extensive knowledge of the juvenile counterpart.

The first part of this review deals with the differences and similarities between AOSD and sJIA. Then, we discuss the various pathophysiological hypotheses arising from recent studies on both diseases. Finally, we expose new data suggesting that patients with AOSD fall into two distinct subgroups (i.e., one with prominent systemic features and one with chronic arthritis).

\section{Are AOSD and SOJIA the same disease?}

Historical considerations may serve as an introduction to this old debate. Indeed, when he first described 22 children with sJIA and named the disease, in 1897, George Frederic Still did not know that an adult with similar symptoms had been reported 1 year earlier [5]. It is only in 1971 that Bywaters reported 14 adult cases and defined AOSD, on the basis of resemblance in clinical and laboratory features [6].

Apart from these considerations, a comparison of the epidemiology, genetic, clinical presentation, and course (shown in Table 1) seems sufficient to convince that AOSD and sJIA are the same disease [7, 8]. Both belong to a continuum that affects children and, to a lesser extent, young adults. However, some differences are reported.

Indeed, by comparing 95 AOSD and 25 sJIA, Pay et al. [9] have described more frequent fever, skin rash, myalgia, sore throat, and weight loss in adults. Liver dysfunction and neutrophilia were also more frequent in adults. Surprisingly, polycyclic sJIA dominated the childhood cases, whereas adults had more frequent chronic course. However, these results were rather inconsistent with previous studies $[8,10]$.

Other differences have been more repeatedly reported. For example, whereas the sex ratio is around 1 in sJIA, women are more likely to be affected by AOSD than men (70 vs. $30 \%$ in rheumatologic cohorts) [11, 12]. This difference could reflect hormonal influence, which is further supported by recurrences or flares during pregnancy and postpartum [13]. As children are quite prevented from hormonal influence before puberty, this could explain the similar occurrence in boys and girls.

Seasonality has been described for sJIA [14], and most authors have considered this variation as an argument for an infectious trigger [15]. In addition, seasonality has also been reported in AOSD [16]. The higher incidence in
Table 1 Comparison of sJIA and AOSD characteristics [7, 8, 100]

\begin{tabular}{|c|c|c|}
\hline Features & SJIA & AOSD \\
\hline \multicolumn{3}{|l|}{ Genetic } \\
\hline Associated HLA & $\begin{array}{l}\text { Bw35, DR2, DR4, } \\
\text { DR5, Dw7 }\end{array}$ & $\begin{array}{l}\text { Bw35, DR2, } \\
\text { DR4, DRB1, } \\
\text { Dw7 }\end{array}$ \\
\hline Polymorphisms & $\begin{array}{l}M I F, I L 6, I L 18, \\
\quad T N F-\alpha\end{array}$ & $M I F, I L 18$ \\
\hline \multicolumn{3}{|l|}{ Epidemiology } \\
\hline Sex ratio female/male & $1 / 1$ & $70 / 30$ \\
\hline Incidence $(/ 100,000 /$ year $)$ & $1.6-23$ & $0.16-0.4$ \\
\hline Seasonality & +++ & \pm \\
\hline \multicolumn{3}{|l|}{ Clinical presentation } \\
\hline Daily spiking fever & $99 \%$ & $94 \%$ \\
\hline Salmon rash & $90 \%$ & $87 \%$ \\
\hline Arthritis & $95 \%$ & $93 \%$ \\
\hline Sore throat & $15 \%$ & $70 \%$ \\
\hline RES hypertrophy & $40-70 \%$ & $50-70 \%$ \\
\hline Serositis & $20-50 \%$ & $20-40 \%$ \\
\hline \multicolumn{3}{|l|}{ Laboratory findings } \\
\hline WBC count $>10,000 / \mathrm{mm}^{3}$ & $90 \%$ & $86 \%$ \\
\hline Elevated ESR & $95 \%$ & $96 \%$ \\
\hline Autoantibodies & No & No \\
\hline $\begin{array}{l}\text { Association with } \\
\text { MHC class II }\end{array}$ & No & No \\
\hline Autoreactive $\mathrm{T}$ cells & No & No \\
\hline Association with MAS & $7-10 \%$ & $12-17 \%$ \\
\hline \multicolumn{3}{|l|}{ Evolution } \\
\hline Monocyclic form & $40 \%$ & $30 \%$ \\
\hline Polycyclic form & $<10 \%$ & $30 \%$ \\
\hline Chronic form & $>50 \%$ & $40 \%$ \\
\hline Carpal ankylosis & $28-50 \%$ & $45-55 \%$ \\
\hline Destructive arthritis & $30 \%$ & $20-25 \%$ \\
\hline Amyloidosis & Possible & Possible \\
\hline \multicolumn{3}{|l|}{ Treatment } \\
\hline Cortiscosteroids efficacy & $50 \%$ & $60 \%$ \\
\hline Response to anakinra & $50-100 \%$ & $50-100 \%$ \\
\hline Response to tocilizumab & $71-85 \%$ & $60-80 \%$ \\
\hline Response to anti-TNF & $30 \%$ & $25 \%$ \\
\hline
\end{tabular}

HLA human leukocyte antigens, RES reticuloendothelial system, $W B C$ white blood cells, ESR erythrocyte sedimentation rate, MAS macrophage activation syndrome, $M H C$ major histocompatibility complex, $T N F$ tumor necrosis factor

children could result from a greater exposure to infectious agents that are typically encountered in childhood and a relative immune immaturity while encountering an antigen for the first time. Conversely, the extremely low incidence of AOSD in elderly patients may be explained by immune system senescence or by a higher protection against infectious agents by memory cells. 
Taken together, these data suggest that sJIA and AOSD are the two expressions of the same disease in different hosts. Children may simply be reacting differently as the result of the first encounter of putative antigens with a more naive immune system.

\section{Is AOSD an infectious disease?}

The initiation of AOSD by an environmental trigger, likely a pathogen, has been suspected because of the infectiouslike clinical presentation. The increased incidence in children and the seasonality of the disease support this hypothesis. As in sJIA, numbers of viruses and bacteria have been isolated in AOSD patients [17-19]. So far, no single environmental trigger has been identified and the lack of an obvious candidate could point to multiple common agents being capable of initiating AOSD. It is proposed that infection(s) can trigger deregulated immune pathways in a genetically predisposed host. This hypothesis can be further suggested by the different courses of AOSD; the monocyclic form being secondary to a unique infection that completely resolves, the polycyclic form resulting from infection/reinfection by different pathogens, and the chronic form being due to chronic infection. In the latter situation, the impossibility for the host to get rid of an antigen may induce a chronic course of AOSD.

Overall, AOSD does not seem to be an infectious disease, but rather an autoinflammatory disease, in which infectious or environmental agents may trigger flare-ups.

\section{The autoinflammatory hypothesis}

\section{AOSD and autoinflammation}

Autoinflammatory diseases affect primarily the innate immune system and are characterized by an inappropriate activation of the phagocytes [20]. Historically, this group comprised Mendelian-inherited single-gene defects disorders, such as cryopyrin (NLRP3)-associated periodic syndromes (CAPS), TNF receptor-associated periodic syndromes (TRAPS), and familial Mediterranean fever [2, 21]. They are characterized by the absence of specific autoantibodies or autoreactive T cells. Like AOSD, the common clinical features include recurrent fever and multisystem inflammation with skin rash, serositis, and arthritis. Later in life, they may also be complicated by amyloidosis. As in AOSD, a dramatic response to IL-1 $\beta$ blockade is characteristic of autoinflammatory disorders $[22,23]$. Nevertheless, some features seem to differentiate AOSD: the longer duration of the exacerbations and the strong association with macrophage activation syndrome
(MAS) [24, 25]. Although some classifications include MAS as an autoinflammatory disorder per se [2], the latter is less likely to occur in the setting of other autoinflammatory diseases than in association with AOSD. Furthermore, most of the autoinflammatory diseases are inherited and due to mutations in a single gene, whereas AOSD does not cluster in families, ethnic groups, or geographic areas. Thus, sJIA and AOSD have been classified as multigenic (or complex) autoinflammatory disorders.

\section{Genetics}

Consistent with this classification, strong associations with MHC class II are lacking in AOSD, although in some populations association with HLA-DR4, HLA-Bw35, or HLA-DRB1 have been occasionally observed [26, 27]. Polymorphisms have been described in genes encoding innate immunity-associated factors and cytokines, such as IL-6, IL-1 $\alpha$, IL1-RN, macrophage inhibitory factor (MIF), or TNF in patients with sJIA [28-30] and IL-18, or MIF in patients with AOSD [31, 32]. Loss-of-function variants in $P 2 R X 7$, which encodes an ATP receptor that regulates IL-1 processing and secretion, have also been reported [33].

Interestingly, no mutation in the genes involved in hereditary autoinflammatory diseases (i.e., NLRP3, NOD2, $M E F V$, or PSTPIP1) has been associated with AOSD [34].

Overall, these polymorphisms are anecdotal but are very likely to have low penetrance. Thus, their contribution to AOSD pathogenesis remains elusive. Conversely, hereditary autoinflammatory diseases have single highly penetrant mutations. Taken together, these data suggest a multigenic pattern in AOSD.

Activation of innate immune pathways

AOSD is marked by prominent neutrophil and macrophage activation, whereas adaptive immunity has a more limited role. Levels of the neutrophil activation marker CD64 and CXCL-8, a chemokine that mobilizes and activates neutrophils, are increased in AOSD [35, 36]. Many markers reflecting the activation of monocyte lineage are correlated with AOSD activity. Macrophage-colony stimulating factor (M-CSF) and interferon (IFN)- $\gamma$, together with calprotectin, MIF, and intracellular adhesion molecule-1 (ICAM1) have also been reported as useful markers for AOSD activity $[35,37]$.

In sJIA, there is an upregulation of innate immune receptors, such as the Nod-like receptor (NLR) NLRC4 and the Toll-like receptor (TLR)5 [38-40]. The TLR7-MyD88 pathway, leading to neutrophil recruitment and Th17 response, is also activated in the dendritic cells of AOSD patients [41, 42]. TLR4 is involved in sJIA pathophysiology through the recognition of S100 calcium-binding 


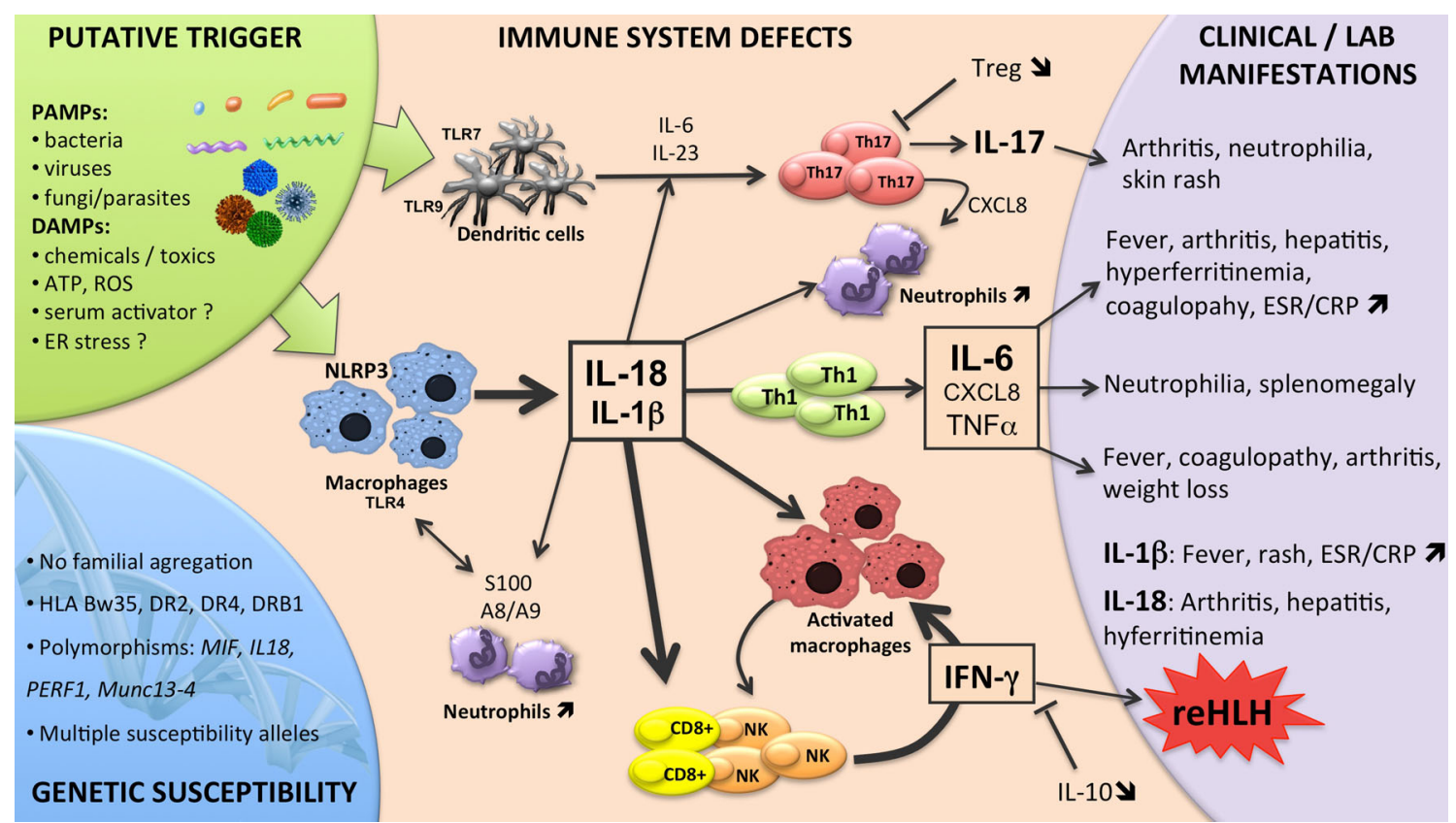

Fig. 1 Current conception of adult-onset Still's disease pathogenesis. Environmental signals (pathogen-associated molecular patterns, PAMPs; or danger-associated molecular patterns, DAMPs) set fire to the innate immune receptors (Toll-like receptors, TLRs; or Nodlike receptors, NLRs), which in turn trigger the activation and secretion of inflammatory cytokines (i.e., IL-1 $\beta$, IL-18, IL-6). Subsequently, Th1 and Th17 adaptive responses are mounted.

proteins [43]. These inflammatory endogenous factors are produced in excess and secreted by activated neutrophils and monocytes. High levels of circulating S100 proteins are a hallmark of active disease. S100-A8/S100-A9 complex triggers TLR4 pathway, leading to an enhancing feedback loop involving inflammatory cytokines, such as IL-1 $\beta$ (Fig. 1).

In addition, NLRP3, the well-known receptor triggering inflammasome formation and subsequent processing of IL$1 \beta$ and IL-18, is highly suspected to play a major role in AOSD [44, 45]. Inflammasomes are multiprotein complexes whose activation depends on the recognition of various stimuli such as pathogen-associated molecular patterns (PAMPs) or danger or damage-associated molecular patterns (DAMPs) [46]. Recent publications have suggested that an abnormal inflammasome pathway could be involved in AOSD pathophysiology.

Antoniou et al. [47] have recently provided evidence for an increased NLRP3-mediated IL-1 $\beta$ production in one case of atypical AOSD. This response was markedly decreased after remission, which is reminiscent of patients with CAPS. Pascual et al. [38] gave the most striking argument for an involvement of IL-1 $\beta$-processing pathway, showing that peripheral blood mononuclear cells of healthy subjects incubated with serum from sJIA patients secrete large amounts of IL-1 $\beta$ and strongly express the genes of
Downstream of IL- $1 \beta$ and IL-18, IL-8, IL-6, and TNF- $\alpha$, along with IL-17, are responsible for the clinical manifestations observed in adult-onset Still's disease. In AOSD, natural killer cells (NK) cells have deficient cytotoxic functions. NK-mediated IFN- $\gamma$ production results from IL-18 stimulation and increases macrophage activation, leading to reactive hemophagocytic lymphohistiocytosis (reHLH), a life-threatening complication of AOSD

innate immunity. These observations suggest that an as-yet unknown trigger-molecule ("activator") is present in the serum of patients and acts as a danger signal.

Other pathways leading to autoinflammation have also been described and need to be explored in the setting of sJIA/AOSD [48-51]. All are susceptible to activate the inflammasome pathway. These include the endoplasmic reticulum stress, abnormal proteostasis through proteasome or immunoproteasome defects, and the ATP/P2X7R pathway [52].

\section{Cytokines}

Consistent with an inflammasome pathway deregulation, IL- $1 \beta$, and IL-18 are central cytokines involved in AOSD pathophysiology.

Interleukin- $1 \beta$, which is elevated in the serum of sJIA and AOSD patients, can upregulate its own transcription, as well as that of IL-6 [53]. This cytokine is responsible for systemic inflammation and can stimulate the destruction of cartilage and bone. Compelling evidence for IL-1 $\beta$ involvement in AOSD has mostly emerged from the dramatic efficacy of IL-1-inhibiting treatments [54, 55]. Concurrent with the clinical response, many disease-associated changes in gene expression in mononuclear cells revert to normal. Also, if given as first-line therapy, in 
sJIA, IL-1 inhibitors can prevent the development of persistent arthritis [56]. Thus, IL-1 is likely to drive the disease onset in AOSD. Moreover, the reduced efficacy of IL1 inhibitors in patients who have already refractory arthritis suggests that IL-1-independent mechanisms arise later in the course of an uncontrolled disease [15].

High levels of IL-18 are observed in the serum, synovial biopsies, lymph nodes, and liver of sJIA and AOSD patients $[35,57,58]$. IL-18 (also known as IFN- $\gamma$-inducing factor) triggers Th1 response and induces the secretion of IFN- $\gamma$ by cytotoxic CD8+ and natural killer (NK) cells. Thus, IL-18 is suggested to play a major role in reactive hemophagocytic lymphohistiocytosis (reHLH) initiation (detailed "The hemophagocytic lymphohistiocytosis hypothesis" in section).

Other cytokines, such as IL- 6 or TNF- $\alpha$, that are downstream of IL-1 $\beta$ and IL-18, are also involved in AOSD pathogenesis $[35,59]$. Levels of IL- 6 are increased in skin specimens and serum of the patients. The effects of IL-6 account for systemic features and for articular manifestations, as it is released by chondrocytes [60]. Notably, neutralizing IL-6 with tocilizumab has led to clinical improvement both on systemic and articular features of AOSD and sJIA [61-63]. In sJIA, response to tocilizumab, an IL-6 blocker, is associated with upregulation of cartilage oligomeric matrix protein (COMP), a marker of cartilage turnover [64].

TNF- $\alpha$ levels are also increased in sera and tissues from AOSD patients but are not correlated with disease activity [65]. Moreover, anti-TNF- $\alpha$ therapy has yielded rather poor results in patients with either sJIA or AOSD [1].

Finally, IL-17, an inflammatory cytokine that amplifies inflammation, stimulates the production of neutrophilrecruiting chemokines (including CXCL-8), and enhances granulopoiesis and myelopoiesis, seems to play an important role in the development of AOSD-related arthritis. The differentiation of naïve $\mathrm{T}$ cells into Th17 cells, producing IL-17, is supported by several cytokines including IL-18, IL-1 $\beta$, IL-6, and IL-23. Recently, Chen et al. [42] have shown that circulating Th17 cells are significantly higher in patients with active untreated AOSD than in healthy controls. The levels of Th17 cells correlated with disease activity, ferritin, and response to treatment. Linking IL-17 with autoinflammation, some gain-of-function mutations of the NLRP3 gene have been shown to lead to increased Th17 differentiation [66]. However, it is still unknown whether Th17 cells are part of the pathogenic mechanism or only downstream of other more complex mechanisms.

Taken together, these data indicate that some mechanisms, which are usually associated with monogenic autoinflammatory diseases, are defective in AOSD. The initial trigger and the exact deregulated mechanisms have still to be discovered. Newly described pathways involved in autoinflammation have also to be explored.
Nevertheless, it is not impossible that various signals set fire to multiple defective pathways leading to the wide spectrum of clinical manifestations and courses of sJIA and AOSD.

\section{The hemophagocytic lymphohistiocytosis hypothesis}

Macrophage activation syndrome is a cytokine storm syndrome characterized by acute inflammation, fever, peripheral cytopenias, organomegaly, hyperferritinemia, hepatitis, and hemophagocytosis [93, 94]. Now, MAS is preferentially termed reHLH, as it is classified within a group of histiocytic disorders collectively known as HLH. In addition to reHLH, this group comprises the familial HLH (FHLH), a constellation of rare autosomal recessive disorders. In FHLH, the uncontrolled expansion of T cells and macrophages has been linked to decreased NK and cytotoxic CD8+ cell function [67]. The best-characterized ones are associated with deficiency in perforin, MUNC134 , syntaxin 11, or Rab27a. All these proteins are part of the network that enables the release of the content of cytotoxic granules from CD8+ or NK cells into infected/target cells. Two hypotheses have been proposed to explain how deficient cytotoxicity leads to HLH [68, 69]. In the first hypothesis, deficient NK and cytotoxic cells fail to kill infected cells, leading to persistent antigenic stimulation and proliferation of $\mathrm{T}$ cells. This results in escalating production of cytokines that stimulate macrophages. In the other hypothesis, abnormal NK and cytotoxic cells fail to provide appropriate apoptotic signals to remove activated macrophages and $\mathrm{T}$ cells during the contraction stage of immune response. Following continuous stimulation by inflammatory cytokines, mostly IFN- $\gamma$, macrophages become hemophagocytic [68].

The association of AOSD with reHLH is supported by many clinical and laboratory findings. Indeed, reHLH and sJIA/AOSD share high fever, hepatosplenomegaly, lymphadenopathy, liver dysfunction, hyperferritinemia, and coagulopathy. The main difference between the two diseases is the neutrophil count, which is elevated in AOSD, whereas it is low in reHLH. Moreover, during AOSD, the decrease in leukocyte count may indicate the onset of reHLH. The skin rash is present in $>90 \%$ of AOSD, whereas it is less common in reHLH (about $45 \%$ ) [24, 70]. Furthermore, overt reHLH has been shown to complicate $7-10$ and $12-17 \%$ of sJIA and AOSD, respectively [15, 24, 71]. Evidence for occult reHLH in a substantial proportion of patients with sJIA or AOSD (up to $50 \%$ ) supports the possibility that HLH and sJIA/AOSD could represent a continuum of severity [72, 73].

Some functional abnormalities have been associated with polymorphisms in the FHLH-associated genes, 
including PRF1 and MUNC13-4 [74, 75]. Likewise, polymorphisms in IRF5, which encodes an IFN regulatory factor and may promote inflammatory macrophage polarization and Th17 response, have been associated with susceptibility to sJIA with reHLH but not without reHLH [76]. Thus, evidence suggests that AOSD with reHLH might belong to the HLH spectrum, with genetic defects accumulating in multiple genes.

Consistent with genetics, deficient NK cell cytotoxicity distinguishes sJIA from other subtypes of JIA [77]. Cytotoxic dysfunction has also been reported in AOSD patients and correlated with the disease activity, as it improved during efficient treatment of AOSD [78-80]. Recently, NK cell dysfunction has been associated with defective signaling by the IL-18 receptor [81]. Indeed, this cytokine plays a major role in priming CD8+ and NK cells, leading to IFN- $\gamma$ secretion and hemophagocytic transformation of macrophages [81]. As stated above, high serum levels of active IL-18 are observed in active AOSD, as in HLH. The bioactivity of IL-18 is regulated by its soluble decoy receptor, IL-18BP. It has been hypothesized that a deregulated imbalance between levels of IL-18 and IL-18BP was a leading cause of HLH [82].

Downstream IFN- $\gamma$ activates macrophages to turn them into hemophagocytes and to produce inflammatory cytokines, such as TNF or IL-6. Serum levels of IFN- $\gamma$ are higher in AOSD with reHLH than without [83]. Liver biopsies from patients with reHLH also demonstrated massive infiltration by IFN- $\gamma$-producing CD8+ cells and hemophagocytes [84]. Compared to that of IL-18, the role of IL-1 in HLH remains to be demonstrated. Nevertheless, inhibiting IL-1 is an effective therapy for sJIA-associated reHLH [71].

Finally, a very recent observation has linked NLRmediated autoinflammation and HLH [85]. A 7-year-old girl presented with features of HLH overlapping with some of sJIA, i.e., recurrent episodes of fever, splenomegaly, occasional evanescent rash, and massive hyperferritinemia. However, articular involvement was not mentioned and laboratory tests showed pancytopenia. She had no NK dysfunction and no mutation in genes associated with FHLH or monogenic autoinflammatory diseases. Instead, a gain-of-function mutation in the gene encoding NLRC4, an inflammasome receptor, was found. The levels of circulating IL-1 $\beta$ and IL-18 were elevated even during clinical quiescence. Therapy with IL-1 inhibitors resulted in rapid improvement. This new observation reinforces the link between autoinflammation, HLH, and sJIA/AOSD.

\section{The defective immunoregulation hypothesis}

Interestingly, anti-inflammatory responses are stimulated in active AOSD, presumably in an attempt to quell inflammation [15]. In untreated early disease, there is an upregulation of genes encoding negative regulators of innate immunity, such as IL-1Ra, IL10, and SOCS3 [86]. IL-10 has immunoregulatory and anti-inflammatory effects, both on innate and adaptive immunity. Although elevated compared with inactive disease, the levels of serum and synovial IL-10 are lower during active sJIA than during active poly-articular JIA [87]. Thus, the antiinflammatory IL-10 response may be deficient in sJIA. In accordance, some polymorphisms of IL-10, associated with decreased function, have been reported in sJIA [29]. Such data are not available in AOSD.

The activation of anti-inflammatory mechanisms is also supported by the M2-polarization of macrophages from patients with sJIA [39, 86, 88]. Contrary to classically activated macrophages (M1) that are highly proinflammatory, M2 macrophages are intended to resolve inflammation, perform scavenger functions, and promote tissue repair. The M2 polarization results from stimulation by anti-inflammatory cytokines, such as IL-4 or IL-10. Macrophages with M2 phenotypes are associated with $\mathrm{Th} 2$ response and are more resistant to apoptosis, like sJIA macrophages [89]. Hemophagocytic bone-marrow macrophages, observed in occult or overt reHLH, express the CD163, a marker of M2 polarization [72]. As M2 polarization is a deactivating program, it is likely induced to suppress the inflammation. Nevertheless, none of these mechanisms seem to be sufficient to resolve the inflammation in SJIA/AOSD.

In addition, the regulatory $\mathrm{T}$ cells (Treg) pathway is another anti-inflammatory mechanism that might be deficient in sJIA/AOSD [90]. Indeed, circulating Treg and transforming growth factor (TGF)- $\beta$ are inversely correlated with AOSD activity and the overall number of Treg is reduced in active sJIA.

Finally, several reports have shown a continued expression of activation markers while sJIA/AOSD was inactive, thus suggesting that quiescence in sJIA/AOSD may only represent a state of compensated inflammation [91]. This has been derived from observations of elevated levels of monocyte surface markers (CD14 and CD16), serum amyloid A, MIF, and IL-18.

Taken together, these results suggest that the pathophysiology of sJIA/AOSD may result not only from the unchained activation of proinflammatory mechanisms but also from defects in the immunoregulation.

\section{The "hyperferritinemic syndrome" hypothesis}

Recently, some authors have proposed to gather four diseases that share similar clinical and laboratory findings and are associated with massive hyperferritinemia into the "hyperferritinemic syndrome" [92]. These four diseases 
are reHLH, AOSD, catastrophic antiphospholipid syndrome, and septic shock. Indeed, there is increasing evidence that ferritin not only reflect the acute phase response but may play critical proinflammatory functions [93]. Indeed, in hepatic stellate cells, exogenous ferritin was shown to activate the NF- $\kappa \mathrm{B}$ pathway, leading to proinflammatory cytokine production, including IL-1 $\beta$ [94]. Mostly, high ferritin levels may contribute to the development of a cytokine storm through a loop mechanism where the inflammatory properties of ferritin are exacerbated. The high levels of ferritin observed during inflammation result from increased production by histiocytes/ macrophages and increased release from damaged hepatocytes. Many cytokines regulate the ferritin synthesis; IL$1 \beta$, IL-18, TNF- $\alpha$, IFN- $\gamma$, and IL- 6 have been reported to stimulate ferritin production. Interestingly, all these cytokines are involved in AOSD pathogenesis, where their levels positively correlate with disease activity, as do ferritin levels. During AOSD, ferritin levels are higher than in several other autoimmune, inflammatory, infectious, or neoplastic diseases. A threshold of five times the normal value is suggestive of AOSD [95]. Nevertheless, serum ferritin is of limited value in diagnosing AOSD but may be useful to monitor disease activity. Conversely, low glycosylated ferritin (i.e., $<20 \%$ ) is considered as a major criterion in Fautrel's classification for the diagnosis of AOSD [96]. However, low glycosylated ferritin may also be associated with reHLH due to other underlying conditions [70]. Yet, the exact role of ferritin and its iso/apoforms remains to be further characterized.

\section{Two subsets of SJIA/AOSD}

Very recently, it has becoming increasingly apparent that patients with sJIA/AOSD fall into two distinct subsets:

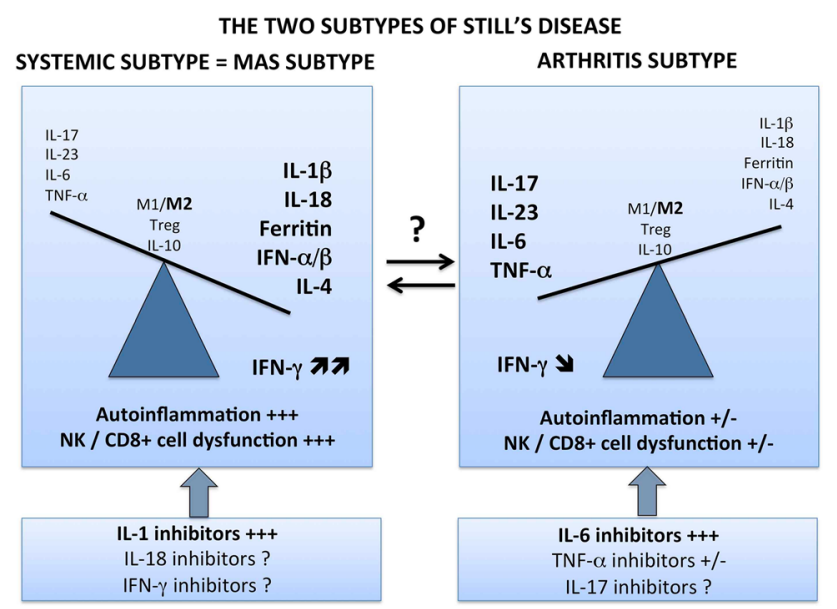

Fig. 2 The two subtypes of AOSD those presenting with systemic features (including increased reHLH occurrence) and those presenting with prominent arthritis. These findings are supported by molecular evidence, cytokine profiles, clinical course, and response to treatment (Fig. 2).

The analysis of transcription profiles in blood mononuclear cells from sJIA patients has revealed a correlation between the «systemic» group and upregulation of the genes of granulopoiesis and innate immunity [86]. Clinical and laboratory findings also distinguish between these two groups; hepatitis, thrombocytopenia, reHLHL, and hyperferritinemia are associated with the «systemic» group, whereas arthritis and thrombocytosis are associated with the «arthritis» group. Accordingly, data from patients or animal models have associated IL-18, IFN- $\gamma$, IL-10, and IL-4 with the «systemic» group, whereas the «arthritis» group was associated with IL-6, IL-17, and IL-23 [83, 97, 98]. For example, in the study by Ichida et al., serum ferritin and IL-18 were lower in AOSD patients with a rheumatoid-arthritis-like presentation (i.e., the «arthritis» group) [98]. The role of IFN- $\gamma$ needs to be further defined as it seems that either too much or to few IFN- $\gamma$ may contribute to the imbalance between the two groups [99]. Finally, when grouped by IL-1Ra response, non-responders were more likely to have arthritis, whereas other parameters like serum ferritin were comparable [33]. As stated above, neutralizing IL-6 with tocilizumab leads to both systemic and articular improvement, whereas IL-1 blockers are less effective on articular features [1].

These early data need to be further assessed in larger cohorts since they may be of the utmost importance for the treatment of AOSD patients. Indeed, identifying AOSD subgroups may lead, in the future, to more personalized treatments by proposing more specific cytokine blockers [12]. One may also ask the question of two different diseases, rather than two subgroups of the same disease. In the near future, basic and clinical studies should try to answer this pending question.

Acknowledgments Dr. Yvan Jamilloux acknowledges the Foundation for the Development of Internal Medicine in Europe (FDIME), the Société Nationale Française de Médecine Interne (SNFMI), and Genzyme for their help in funding his PhD research project. Dr. Yvan Jamilloux is supported by a "poste d'accueil" at INSERM.

Conflict of interest The authors declare that they have no conflict of interest.

\section{References}

1. Gerfaud-Valentin M, Jamilloux Y, Iwaz J, Sève P. Adult-onset Still's disease. Autoimmun Rev. 2014;13:708-22.

2. Kastner DL, Aksentijevich I, Goldbach-Mansky R. Autoinflammatory disease reloaded: a clinical perspective. Cell. 2010;140:784-90. 
3. Borchers AT, Selmi C, Cheema G, Keen CL, Shoenfeld Y, Gershwin ME. Juvenile idiopathic arthritis. Autoimmun Rev. 2006;5:279-98.

4. Lin Y-T, Wang C-T, Gershwin ME, Chiang B-L. The pathogenesis of oligoarticular/polyarticular vs systemic juvenile idiopathic arthritis. Autoimmun Rev. 2011;10:482-9.

5. Still GF. On a form of chronic joint disease in children. Medico Chir Trans. 1897;80(47-60):9.

6. Bywaters EG. Still's disease in the adult. Ann Rheum Dis. 1971;30:121-33.

7. Uppal SS, Pande IR, Kumar A, Kailash S, Sekharan NG, Adya $\mathrm{CM}$, et al. Adult onset Still's disease in northern India: comparison with juvenile onset Still's disease. Br J Rheumatol. 1995;34:429-34.

8. Luthi F, Zufferey P, Hofer MF, So AK. “Adolescent-onset Still's disease": characteristics and outcome in comparison with adultonset Still's disease. Clin Exp Rheumatol. 2002;20:427-30.

9. Pay S, Türkçapar N, Kalyoncu M, Simşek I, Beyan E, Ertenli I, et al. A multicenter study of patients with adult-onset Still's disease compared with systemic juvenile idiopathic arthritis. Clin Rheumatol. 2006;25:639-44.

10. Cabane J, Michon A, Ziza JM, Bourgeois P, Blétry O, Godeau P, et al. Comparison of long term evolution of adult onset and juvenile onset Still's disease, both followed up for more than 10 years. Ann Rheum Dis. 1990;49:283-5.

11. Pouchot J, Sampalis JS, Beaudet F, Carette S, Decary F, SalusinskySternbach M, et al. Adult Still's disease: manifestations, disease course, and outcome in 62 patients. Medicine. 1991;70:118-36.

12. Gerfaud-Valentin M, Maucort-Boulch D, Hot A, Iwaz J, Ninet J, Durieu I, et al. Adult-onset still disease: manifestations, treatment, outcome, and prognostic factors in 57 patients. Medicine. 2014;93:91-9.

13. Gerfaud-Valentin M, Hot A, Huissoud C, Durieu I, Broussolle C, Seve P. Adult-onset Still's disease and pregnancy: about ten cases and review of the literature. Rheumatol Int. 2014;34(6): 867-71.

14. Uziel Y, Pomeranz A, Brik R, Navon P, Mukamel M, Press J, et al. Seasonal variation in systemic onset juvenile rheumatoid arthritis in Israel. J Rheumatol. 1999;26:1187-9.

15. Mellins ED, Macaubas C, Grom AA. Pathogenesis of systemic juvenile idiopathic arthritis: some answers, more questions. Nat Rev Rheumatol. 2011;7:416-26.

16. Lee JY-Y, Hsu C-K, Liu M-F, Chao S-C. Evanescent and persistent pruritic eruptions of adult-onset still disease: a clinical and pathologic study of 36 patients. Semin Arthritis Rheum. 2012;42:317-26.

17. Wouters JM, van der Veen J, van de Putte LB, de Rooij DJ. Adult onset Still's disease and viral infections. Ann Rheum Dis. 1988;47:764-7.

18. Escudero FJ, Len O, Falcó V, de Sevilla TF, Sellas A. Rubella infection in adult onset Still's disease. Ann Rheum Dis. 2000;59:493.

19. Perez C, Artola V. Adult Still's disease associated with Mycoplasma pneumoniae infection. Clin Infect Dis Off Publ Infect Dis Soc Am. 2001;32:E105-6.

20. Masters SL, Simon A, Aksentijevich I, Kastner DL. Horror autoinflammaticus: the molecular pathophysiology of autoinflammatory disease (*). Annu Rev Immunol. 2009;27:621-68.

21. Grateau G, Hentgen V, Stojanovic KS, Jéru I, Amselem S, Steichen O. How should we approach classification of autoinflammatory diseases? Nat Rev Rheumatol. 2013;9:624-9.

22. Koné-Paut I, Piram M. Targeting interleukin-1 $\beta$ in CAPS (cryopyrin-associated periodic) syndromes: what did we learn? Autoimmun Rev. 2012;12:77-80.

23. Hoffman HM. Therapy of autoinflammatory syndromes. J Allergy Clin Immunol. 2009;124:1129-1138; quiz 1139-1140.
24. Arlet J-B, Le THD, Marinho A, Amoura Z, Wechsler B, Papo T, et al. Reactive haemophagocytic syndrome in adult-onset Still's disease: a report of six patients and a review of the literature. Ann Rheum Dis. 2006;65:1596-601.

25. Min J-K, Cho C-S, Kim H-Y, Oh E-J. Bone marrow findings in patients with adult Still's disease. Scand J Rheumatol. 2003;32: $119-21$.

26. Terkeltaub R, Esdaile JM, Décary F, Harth M, Lister J, Lapointe N. HLA-Bw35 and prognosis in adult Still's disease. Arthritis Rheum. 1981;24:1469-72.

27. Joung CI, Lee HS, Lee SW, Kim CG, Song YH, Jun JB, et al. Association between HLA-DR B1 and clinical features of adult onset Still's disease in Korea. Clin Exp Rheumatol. 2003;21:489-92.

28. Fishman D, Faulds G, Jeffery R, Mohamed-Ali V, Yudkin JS, Humphries $\mathrm{S}$, et al. The effect of novel polymorphisms in the interleukin-6 (IL-6) gene on IL-6 transcription and plasma IL-6 levels, and an association with systemic-onset juvenile chronic arthritis. J Clin Invest. 1998;102:1369-76.

29. Möller JC, Paul D, Ganser G, Range U, Gahr M, Kelsch R, et al. IL10 promoter polymorphisms are associated with systemic onset juvenile idiopathic arthritis (SoJIA). Clin Exp Rheumatol. 2010;28:912-8.

30. Stock CJW, Ogilvie EM, Samuel JM, Fife M, Lewis CM, Woo P. Comprehensive association study of genetic variants in the IL-1 gene family in systemic juvenile idiopathic arthritis. Genes Immun. 2008;9:349-57.

31. Sugiura T, Kawaguchi Y, Harigai M, Terajima-Ichida H, Kitamura Y, Furuya T, et al. Association between adult-onset Still's disease and interleukin-18 gene polymorphisms. Genes Immun. 2002;3:394-9.

32. Wang F-F, Huang X-F, Shen N, Leng L, Bucala R, Chen S-L, et al. A genetic role for macrophage migration inhibitory factor (MIF) in adult-onset Still's disease. Arthritis Res Ther. 2013; 15:R65.

33. Gattorno M, Piccini A, Lasigliè D, Tassi S, Brisca G, Carta S, et al. The pattern of response to anti-interleukin-1 treatment distinguishes two subsets of patients with systemic-onset juvenile idiopathic arthritis. Arthritis Rheum. 2008;58:1505-15.

34. Kim JJ, Kim J-K, Shim S-C, Choe J-Y, Kim T-H, Jun J-B, et al. MEFV gene mutations and their clinical significance in Korean patients with adult-onset Still's disease. Clin Exp Rheumatol. 2013:31:60-3.

35. Choi J-H, Suh C-H, Lee Y-M, Suh Y-J, Lee S-K, Kim S-S, et al. Serum cytokine profiles in patients with adult onset Still's disease. J Rheumatol. 2003;30:2422-7.

36. Komiya A, Matsui T, Nogi S, Iwata K, Futami H, Takaoka H, et al. Neutrophil CD64 is upregulated in patients with active adult-onset Still's disease. Scand J Rheumatol. 2012;41:156-8.

37. Matsui K, Tsuchida T, Hiroishi K, Tominaga K, Hayashi N, Hada $\mathrm{T}$, et al. High serum level of macrophage-colony stimulating factor (M-CSF) in adult-onset Still's disease. Rheumatology. 1999;38:477-8.

38. Pascual V, Allantaz F, Arce E, Punaro M, Banchereau J. Role of interleukin-1 (IL-1) in the pathogenesis of systemic onset juvenile idiopathic arthritis and clinical response to IL-1 blockade. J Exp Med. 2005;201:1479-86.

39. Ogilvie EM, Khan A, Hubank M, Kellam P, Woo P. Specific gene expression profiles in systemic juvenile idiopathic arthritis. Arthritis Rheum. 2007;56:1954-65.

40. Barnes MG, Grom AA, Thompson SD, Griffin TA, Pavlidis P, Itert L, et al. Subtype-specific peripheral blood gene expression profiles in recent-onset juvenile idiopathic arthritis. Arthritis Rheum. 2009;60:2102-12.

41. Chen D-Y, Lin C-C, Chen Y-M, Lan J-L, Hung W-T, Chen $\mathrm{H}-\mathrm{H}$, et al. Involvement of TLR7 MyD88-dependent signaling 
pathway in the pathogenesis of adult-onset Still's disease. Arthritis Res Ther. 2013;15:R39.

42. Chen D-Y, Chen Y-M, Lan J-L, Lin C-C, Chen H-H, Hsieh C-W. Potential role of Th17 cells in the pathogenesis of adultonset Still's disease. Rheumatology. 2010;49:2305-12.

43. Frosch M, Ahlmann M, Vogl T, Wittkowski H, Wulffraat N, Foell D, et al. The myeloid-related proteins 8 and 14 complex, a novel ligand of toll-like receptor 4 , and interleukin-1beta form a positive feedback mechanism in systemic-onset juvenile idiopathic arthritis. Arthritis Rheum. 2009;60:883-91.

44. Rossi-Semerano L, Koné-Paut I. Is Still's disease an autoinflammatory syndrome? Int J Inflamm. 2012;2012:480373.

45. Hayem F, Hayem G. Still's disease and the mitochondrion: the other face of an old friend? Med Hypotheses. 2012;79:136-7.

46. Jamilloux Y, Henry T. The inflammasomes: platforms of innate immunity. Méd Sci MS. 2013;29:975-84.

47. Antoniou KM, Margaritopoulos GA, Giannarakis I, Choulaki C, Fountoulakis N, Siafakas NM, et al. Adult onset Still's Disease: a case report with a rare clinical manifestation and pathophysiological correlations. Case Rep Med. 2013;2013:981232.

48. Menu P, Mayor A, Zhou R, Tardivel A, Ichijo H, Mori K, et al. ER stress activates the NLRP3 inflammasome via an UPRindependent pathway. Cell Death Dis. 2012;3:e261.

49. Shin JN, Fattah EA, Bhattacharya A, Ko S, Eissa NT. Inflammasome activation by altered proteostasis. J Biol Chem. 2013;288:35886-95.

50. Prahalad S, Kingsbury DJ, Griffin TA, Cooper BL, Glass DN, Maksymowych WP, et al. Polymorphism in the MHC-encoded LMP7 gene: association with JRA without functional significance for immunoproteasome assembly. J Rheumatol. 2001;28:2320-5.

51. Savic S, Dickie LJ, Wittmann M, McDermott MF. Autoinflammatory syndromes and cellular responses to stress: pathophysiology, diagnosis and new treatment perspectives. Best Pract Res Clin Rheumatol. 2012;26:505-33.

52. Park H, Bourla AB, Kastner DL, Colbert RA, Siegel RM. Lighting the fires within: the cell biology of autoinflammatory diseases. Nat Rev Immunol. 2012;12:570-80.

53. Goldbach-Mansky R, Kastner DL. Autoinflammation: the prominent role of IL-1 in monogenic autoinflammatory diseases and implications for common illnesses. J Allergy Clin Immunol. 2009;124:1141-1149; quiz 1150-1151.

54. Lequerré T, Quartier P, Rosellini D, Alaoui F, De Bandt M, Mejjad $\mathrm{O}$, et al. Interleukin-1 receptor antagonist (anakinra) treatment in patients with systemic-onset juvenile idiopathic arthritis or adult onset Still disease: preliminary experience in France. Ann Rheum Dis. 2008;67:302-8.

55. Giampietro C, Fautrel B. Anti-interleukin-1 agents in adult onset Still's disease. Int J Inflamm. 2012;2012:317820.

56. Nigrovic PA, Mannion M, Prince FHM, Zeft A, Rabinovich CE, van Rossum MAJ, et al. Anakinra as first-line disease-modifying therapy in systemic juvenile idiopathic arthritis: report of fortysix patients from an international multicenter series. Arthritis Rheum. 2011;63:545-55.

57. Rooney T, Murphy E, Benito M, Roux-Lombard P, FitzGerald $\mathrm{O}$, Dayer J-M, et al. Synovial tissue interleukin-18 expression and the response to treatment in patients with inflammatory arthritis. Ann Rheum Dis. 2004;63:1393-8.

58. Conigliaro P, Priori R, Bombardieri M, Alessandri C, Barone F, Pitzalis C, et al. Lymph node IL-18 expression in adult-onset Still's disease. Ann Rheum Dis. 2009;68:442-3.

59. Chen D-Y, Lan J-L, Lin F-J, Hsieh T-Y. Proinflammatory cytokine profiles in sera and pathological tissues of patients with active untreated adult onset Still's disease. J Rheumatol. 2004;31:2189-98.

60. Ryu J-H, Yang S, Shin Y, Rhee J, Chun C-H, Chun J-S. Interleukin-6 plays an essential role in hypoxia-inducible factor $2 \alpha-$ induced experimental osteoarthritic cartilage destruction in mice. Arthritis Rheum. 2011;63:2732-43.

61. Puéchal X, DeBandt M, Berthelot J-M, Breban M, Dubost J-J, Fain O, et al. Tocilizumab in refractory adult Still's disease. Arthritis Care Res. 2011;63:155-9.

62. Cipriani P, Ruscitti P, Carubbi F, Pantano I, Liakouli V, Berardicurti $\mathrm{O}$, et al. Tocilizumab for the treatment of adult-onset Still's disease: results from a case series. Clin Rheumatol. 2014;33:49-55.

63. De Benedetti F, Brunner HI, Ruperto N, Kenwright A, Wright S, Calvo I, et al. Randomized trial of tocilizumab in systemic juvenile idiopathic arthritis. N Engl J Med. 2012;367:2385-95.

64. Nakajima S, Naruto $T$, Miyamae $T$, Imagawa $T$, Mori $M$, Nishimaki $\mathrm{S}$, et al. Improvement of reduced serum cartilage oligomeric matrix protein levels in systemic juvenile idiopathic arthritis patients treated with the anti-interleukin-6 receptor monoclonal antibody tocilizumab. Mod Rheumatol Jpn Rheum Assoc. 2009;19:42-6.

65. Hoshino T, Ohta A, Yang D, Kawamoto M, Kikuchi M, Inoue $\mathrm{Y}$, et al. Elevated serum interleukin 6, interferon-gamma, and tumor necrosis factor-alpha levels in patients with adult Still's disease. J Rheumatol. 1998;25:396-8.

66. Meng G, Zhang F, Fuss I, Kitani A, Strober W. A mutation in the Nlrp3 gene causing inflammasome hyperactivation potentiates Th17 cell-dominant immune responses. Immunity. 2009;30:860-74.

67. Filipovich AH. The expanding spectrum of hemophagocytic lymphohistiocytosis. Curr Opin Allergy Clin Immunol. 2011;11: 512-6.

68. Voskoboinik I, Smyth MJ, Trapani JA. Perforin-mediated targetcell death and immune homeostasis. Nat Rev Immunol. 2006;6:940-52.

69. Stepp SE, Mathew PA, Bennett M, de Saint Basile G, Kumar V. Perforin: more than just an effector molecule. Immunol Today. 2000;21:254-6.

70. Fardet L, Galicier L, Vignon-Pennamen M-D, Regnier S, Noguera ME, de Labarthe A, et al. Frequency, clinical features and prognosis of cutaneous manifestations in adult patients with reactive haemophagocytic syndrome. Br J Dermatol. 2010;162: 547-53.

71. Ravelli A, Grom AA, Behrens EM, Cron RQ. Macrophage activation syndrome as part of systemic juvenile idiopathic arthritis: diagnosis, genetics, pathophysiology and treatment. Genes Immun. 2012;13:289-98.

72. Behrens EM, Beukelman T, Paessler M, Cron RQ. Occult macrophage activation syndrome in patients with systemic juvenile idiopathic arthritis. J Rheumatol. 2007;34:1133-8.

73. Efthimiou P, Kadavath S, Mehta B. Life-threatening complications of adult-onset Still's disease. Clin Rheumatol. 2014;33: 305-14.

74. Vastert SJ, van Wijk R, D’Urbano LE, de Vooght KMK, de Jager W, Ravelli A, et al. Mutations in the perforin gene can be linked to macrophage activation syndrome in patients with systemic onset juvenile idiopathic arthritis. Rheumatology. 2010;49:441-9.

75. Zhang K, Biroschak J, Glass DN, Thompson SD, Finkel T, Passo $\mathrm{MH}$, et al. Macrophage activation syndrome in patients with systemic juvenile idiopathic arthritis is associated with MUNC13-4 polymorphisms. Arthritis Rheum. 2008;58:2892-6.

76. Yanagimachi M, Naruto T, Miyamae T, Hara T, Kikuchi M, Hara R, et al. Association of IRF5 polymorphisms with susceptibility to macrophage activation syndrome in patients with juvenile idiopathic arthritis. J Rheumatol. 2011;38:769-74.

77. Villanueva J, Lee S, Giannini EH, Graham TB, Passo MH, Filipovich A, et al. Natural killer cell dysfunction is a distinguishing feature of systemic onset juvenile rheumatoid arthritis 
and macrophage activation syndrome. Arthritis Res Ther. 2005;7:R30-7.

78. Lee S-J, Cho Y-N, Kim T-J, Park S-C, Park D-J, Jin H-M, et al. Natural killer T cell deficiency in active adult-onset Still's Disease: correlation of deficiency of natural killer T cells with dysfunction of natural killer cells. Arthritis Rheum. 2012;64:2868-77.

79. Park JH, Kim H-S, Lee JS, Kim JJ, Jung K-H, Park Y-W, et al. Natural killer cell cytolytic function in Korean patients with adult-onset Still's disease. J Rheumatol. 2012;39:2000-7.

80. Shimizu M, Sakakibara Y, Kawano M, Yachie A. Transient impairment of NK cell function in an infant born to a mother with adult-onset Still's disease: perinatal effect of maternal IL18. Clin Immunol. 2012;143:273-4.

81. De Jager W, Vastert SJ, Beekman JM, Wulffraat NM, Kuis W, Coffer PJ, et al. Defective phosphorylation of interleukin-18 receptor beta causes impaired natural killer cell function in systemic-onset juvenile idiopathic arthritis. Arthritis Rheum. 2009;60:2782-93.

82. Mazodier K, Marin V, Novick D, Farnarier C, Robitail S, Schleinitz N, et al. Severe imbalance of IL-18/IL-18BP in patients with secondary hemophagocytic syndrome. Blood. 2005;106:3483-9.

83. Shimizu M, Yokoyama T, Yamada K, Kaneda H, Wada H, Wada $\mathrm{T}$, et al. Distinct cytokine profiles of systemic-onset juvenile idiopathic arthritis-associated macrophage activation syndrome with particular emphasis on the role of interleukin-18 in its pathogenesis. Rheumatology. 2010;49:1645-53.

84. Billiau AD, Roskams T, Van Damme-Lombaerts R, Matthys P, Wouters C. Macrophage activation syndrome: characteristic findings on liver biopsy illustrating the key role of activated, IFN-gamma-producing lymphocytes and IL-6- and TNF-alphaproducing macrophages. Blood. 2005;105:1648-51.

85. Canna S, de Jesus AA, Deng Z, Gouni S, Marrero B, Brooks S, et al. A157: macrophage activation syndrome-like illness due to an activating mutation in NLRC4. Arthritis Rheumatol. 2014; 66(Suppl 11):S203.

86. Fall N, Barnes M, Thornton S, Luyrink L, Olson J, Ilowite NT, et al. Gene expression profiling of peripheral blood from patients with untreated new-onset systemic juvenile idiopathic arthritis reveals molecular heterogeneity that may predict macrophage activation syndrome. Arthritis Rheum. 2007;56:3793-804.

87. De Jager W, Hoppenreijs EPAH, Wulffraat NM, Wedderburn LR, Kuis W, Prakken BJ. Blood and synovial fluid cytokine signatures in patients with juvenile idiopathic arthritis: a crosssectional study. Ann Rheum Dis. 2007;66:589-98.

88. Macaubas C, Nguyen KD, Peck A, Buckingham J, Deshpande $\mathrm{C}$, Wong E, et al. Alternative activation in systemic juvenile idiopathic arthritis monocytes. Clin Immunol. 2012;142:362-72.
89. Srivastava S, Macaubas C, Deshpande C, Alexander HC, Chang $\mathrm{S}-\mathrm{Y}$, Sun Y, et al. Monocytes are resistant to apoptosis in systemic juvenile idiopathic arthritis. Clin Immunol. 2010;136:257-68.

90. Chen D-Y, Chen Y-M, Chen H-H, Hsieh C-W, Lin C-C, Lan J-L. The associations of circulating CD4 + CD25high regulatory $\mathrm{T}$ cells and TGF- $\beta$ with disease activity and clinical course in patients with adult-onset Still's disease. Connect Tissue Res. 2010;51:370-7.

91. Macaubas C, Nguyen K, Deshpande C, Phillips C, Peck A, Lee $\mathrm{T}$, et al. Distribution of circulating cells in systemic juvenile idiopathic arthritis across disease activity states. Clin Immunol. 2010;134:206-16.

92. Rosário C, Zandman-Goddard G, Meyron-Holtz EG, D’Cruz DP, Shoenfeld Y. The hyperferritinemic syndrome: macrophage activation syndrome, Still's disease, septic shock and catastrophic antiphospholipid syndrome. BMC Med. 2013;11:185.

93. Mehta B, Efthimiou P. Ferritin in adult-onset still's disease: just a useful innocent bystander? Int J Inflamm. 2012;2012:298405.

94. Ruddell RG, Hoang-Le D, Barwood JM, Rutherford PS, Piva TJ, Watters DJ, et al. Ferritin functions as a proinflammatory cytokine via iron-independent protein kinase $\mathrm{C}$ zeta/nuclear factor kappaB-regulated signaling in rat hepatic stellate cells. Hepatology. 2009;49:887-900.

95. Ota T, Higashi S, Suzuki H, Eto S. Increased serum ferritin levels in adult Still's disease. Lancet. 1987;1:562-3.

96. Fautrel B, Zing E, Golmard J-L, Le Moel G, Bissery A, Rioux $\mathrm{C}$, et al. Proposal for a new set of classification criteria for adultonset still disease. Medicine. 2002;81:194-200.

97. Shimizu M, Nakagishi Y, Yachie A. Distinct subsets of patients with systemic juvenile idiopathic arthritis based on their cytokine profiles. Cytokine. 2013;61:345-8.

98. Ichida H, Kawaguchi Y, Sugiura T, Takagi K, Katsumata Y, Gono T, et al. Clinical manifestations of adult-onset still's disease presenting with erosive arthritis: association with low levels of ferritin and IL-18. Arthritis Care Res (Hoboken). 2013. doi:10.1002/acr.22194.

99. Canna SW. Interferon- $\gamma$ : friend or foe in systemic juvenile idiopathic arthritis and adult Still's Disease. Arthritis Rheumatol. 2014;66:1072-6.

100. Tanaka S, Matsumoto Y, Ohnishi H, Maeda M, Nishioka K, Kashiwazaki S, et al. Comparison of clinical features of childhood and adult onset Still's disease. Ryūmachi Rheum. 1991;31:511-8. 